\title{
Biological Differences between Normal and Tumoral Tissue Not Always an Increase of Expression is Indicator of Poor Prognosis
}

\section{Ruibal A*, Aguiar P and Herranz M}

Nuclear Medicine Service, IDIS, University Hospital, Universidade de Santiago de Compostela, Spain

*Corresponding author: Ruibal A, Nuclear Medicine Service, IDIS, University Hospital, Universidade de Santiago de Compostela, Spain, Tel: +34981950088; E-mail: Alvaro.Ruibal.Morell@sergas.es

Received date: September 19, 2016; Accepted date: September 20, 2016; Published date: September 21, 2016

Copyright: () 2016 Ruibal A, et al. This is an open-access article distributed under the terms of the Creative Commons Attribution License, which permits unrestricted use, distribution, and reproduction in any medium, provided the original author and source are credited.

\section{Editorial}

Tumor markers (TM) can be classified into two main groups: a) Secretion TM, preferably dosed in blood and useful in monitoring patients for early detection of recurrence and/or metastasis, as well as better knowledge of the therapeutic efficacy; b) Tissue TM, including biochemical-molecular parameters, which, analyzed in the tissue itself, allow tumor characterization about their prognosis and therapy. An attractive possibility of study is to compare the behaviour of a possible $\mathrm{TM}$ in normal and tumoral tissues in order to find conclusions of practical interest.

In malignant lung disease, adhesion molecules are an attractive field of interest and within those, we can stand out CD44. CD44 is a surface adhesion molecule expressed in many normal tissues by cells of different origin and involved in some physiological processes. CD44 exists in a standard form (CD44s) and in multiple isoforms (CD44v) and related with different features of the tumor evolution. For instance, CD44v6 regulates ras/mitogen-activated protein kinase (MAPK) signalling, playing an important role in the transition from normal to transformed phenotypes [1], and some authors have described the value of CD44v6 expression as a parameter of poor survival patients with in non-small cell lung cancer [2]. Similarly, CD44 promotes Kras-dependent lung adenocarcinoma [3].

Hyaluronic acid (HA) is a linear unsulfated glycosaminoglycan ubiquitously expressed, who plays a role in some physiological functions as cell adhesion, migration and differentiation. It is a critical component of cancer microenvironment and increases progression and aggressiveness of tumors. Its elevated production can induce epithelial to mesenchymal-like transition, and therefore it can contribute to tumorigenesis, as well as, increase resistance to certain epidermal growth factor receptor inhibitors [4]. There are different receptors for $\mathrm{HA}$, being CD44 the most important.

Studying CD44s, CD44v5 and CD44v6 expression in cell surface membranes, using Enzyme Immuno Assay (EIA) in patients with nonsmall cell lung carcinomas (squamous and lung adenocarcinomas) and normal lung samples removed from a surrounding tissue region at Least $2 \mathrm{~cm}$ away from the tumors, and macroscopically free from neoplastic growth, we observe the following: In normal pulmonary tissue, we cannot find differences in the positive percentages of CD44s, CD44v5 and CD44v6 related to patient's tumor. However, when comparing different biological parameters between normal and tumoral tissues, we were able to find two common and opposing facts:

1. Cytosolic concentrations of cathepsin D were always higher in the normal tissue than in the tumor, regardless of tumoral subtype.

2. HA cytosolic and membrane concentrations were always higher in tumoral than in normal samples.
This different behaviour can help to explain and understand the value of these parameters as tumor markers. So, and in relation to cathepsin D, we know that their high cytosolic levels were associated with good outcome squamous lung carcinomas [5] and the same has been found when messenger RNA was analysed [6]. That is, it shows a different behaviour than might suspect a priori.

About HA, we know that induce EMT through either TGF-1 and EGF. TGF-1 up-regulates the expression of Hyaluronan synthethase and promotes the expression of CD44, which interacts with EGFR, ensuing the activation of the downstream AKT and ERK pathways. Those are the mechanisms of TGF-1 to induce epithelial-mesenchymal transition [7]. Strong HA staining intensity is associated with cancer cells and a direct association was observed in tumors between high percentages of HA and elevated MicroVessel Density (MVD) in tumoral stroma. In lung tumors there was a significant association between better survival and low HA levels, and the same occurs in patients with gastric and colorectal cancer, whereas in invasive breast cancer, high HA cytosolic levels are associated with longer relapse-free survival time in patients with ductal subtype, as well as those without any type of systemic adjuvant treatment [8]. Similar happens with malignant mesothelioma, where high effusion levels of HA are associated with a significantly longer median survival than those with low levels [9]. This different behaviour than expected also can be found with matrix metallo-proteases [10].

In conclusion and summarizing all described above, the comparative study of different biological parameters between tumor and non-tumor tissues from the same patient, may be useful for understand the malignant transformation, and predict the value of some of them as candidate tumor markers. However, no always a biological behaviour is correlated with their clinical value.

\section{References}

1. Cheng C, Yaffe MB, Sharp PA (2006) A positive feedback loop couples Ras activation and CD44 alterantive splincing. Genes Dev 20: 1715-1720.

2. Jiang H, Zhao W, Shao W (2014) Prognostic value of CD44 and CD44v6 expression in patients with non-small cell lung cancer: Meta-analysis. Tumor Biol 35: 7383-7389.

3. Zhao P, Damerow MS, Stern P, Liu AH, Sweet-Cordero A, et al. (2012) CD44 promotes Kras-dependent lung adenocarcinoma. Oncogene 32. 5186-5190.

4. Chow G, Tauler J, Mulshine JL (2010) Cytokines and growth factors stimulate hyaluronan production: role of hyaluronan in epithelial to mesenchymal-like transition in non-small cell lung cancer. J Biomed Biotechnol pp: 1-11.

5. Ruibal A, Nunez MI, Rio MC, García DS, Rodriguez J, et al. (2003) Cytosolic cathepsin D levels in squamous carcinomas of the lung. Med Clin 120: 81-84. 
Citation: Ruibal A, Aguiar P, Herranz M (2016) Biological Differences between Normal and Tumoral Tissue Not Always an Increase of Expression is Indicator of Poor Prognosis. Lung Dis Treat 2: e107. doi:10.4172/2472-1018.1000e107

Page 2 of 2

6. Shubin AV, Demidyuk IV, Kurinov AM, Demkin VV, Vinogradova TV, et al (2010) Cathepsin D messenger RNA is downregulated in human lung cancer. Biomarkers 15: 608-613.

7. Li L, Qi L, Liang Z, Song W, Liu Y, et al. (2015) Transforming growth factor betal induces EMT by the transactivation of epidermal growth factor signaling through HA/CD44 in lung and breast cancer cells. Int J Mol Med 36: 113-122.

8. Corte MD, Gonzalez LO, Lamelas ML, Alvarez A, Junquera S, et al. (2006) Expression and clinical significance of cytosolic hyaluronan levels in invasive breast cancer. Breast Cancer Res Treat 97: 329-337.
9. Creaney J, Dick IM, Segal A, Musk AW, Robinson BW (2013) Pleural effusion hyaluronic acid as a prognostic marker in pleural malignat mesothelioma. Lung Cancer 82: 491-498.

10. Lopez-Otin C, Palavalli LH, Samuels Y (2009) Protective roles of matrix metalloproteinases; from mouse models to human cancer. Cell Cycle 8: 3657-3662. 